\title{
PRESSURE WORK EFFECT ON NATURAL CONVECTION FLOW FROM A VERTICAL CIRCULAR CONE WITH SUCTION AND NON-UNIFORM SURFACE TEMPERATURE
}

\author{
M. A. Alim ${ }^{1 *}$, Md. M. Alam ${ }^{2}$ and Md. M. K. Chowdhury ${ }^{1}$ \\ ${ }^{1}$ Department of Mathematics, Bangladesh University of Engineering and Technology, \\ Dhaka-1000, Bangladesh. \\ ${ }^{2}$ Department of Mathematics, Dhaka University of Engineering and Technology, \\ Gazipur-1700, Bangladesh. \\ *Corresponding address: maalim@math.buet.ac.bd
}

\begin{abstract}
Laminar free convection from a vertical circular cone maintained at non-uniform surface temperature with effects of suction and pressure work are considered. Non-similarity solutions for boundary layer equations are found to exist when the surface temperature follows the power law variations with the distance measured from the leading edge. The numerical solutions of the transformed non-similar boundary layer equations are obtained by using a finite difference method with Keller Box scheme. Solutions obtained in terms of skin-friction, local rate of heat transfer, velocity and temperature profiles for the values of Prandtl number, pressure work parameter and temperature gradient are displayed in both graphical and tabular forms.
\end{abstract}

Keywords: Free convection, Viscous dissipation, Boussinesq approximation, Temperature gradient, Pressure work.

\section{INTRODUCTION}

Theoretical studies on laminar free convection flow on axisymmetric bodies have received wider attention, especially in case of non-uniform surface temperature and surface heat flux distributions. Mark and Prins ${ }^{1}$ developed the general relations for similar solutions on isothermal axisymmetric forms and showed that for the flow past a vertical cone has such a solution. Approximate boundary layer techniques were utilized to arrive at an expression for the dimensionless heat transfer. Braun et al. ${ }^{2}$ contributed two more isothermal axisymmetric bodies for which similar solutions exist, and used an integral method to provide heat transfer results for these and the cone over a wide range of Prandtl number. In the above investigation, the authors obtained the results by numerical integration of the differential equations for fluid having Prandtl number 0.72 . The similarity solutions for free convection from the vertical cone have been exhausted by Hering and Grosh ${ }^{3}$. They showed that the similarity solutions to the boundary layer equations for a cone exist when the wall temperature distribution is a power function of distance along a cone ray. In their paper they presented the results for isothermal surface as well as for the surface maintained at the temperature varying linearly with the distance measured from the apex of the cone for Prandtl number 0.7. Later, Hering $^{4}$ extended the analysis to investigate for low Prandtl number fluids. On the other hand, Roy ${ }^{5}$ has studied the same problem for the high values of the Prandtl number.

\footnotetext{
Nomenclature

$C_{p} \quad:$ Specific heat at constant pressure.

$C_{f x} \quad:$ Local skin friction.

$f \quad$ : Dimensionless stream function

$g \quad:$ Acceleration due to gravity.

$G r_{x} \quad$ : The local Grashof number.

$k \quad$ : Thermal conductivity of the fluid.

$n \quad:$ The temperature gradient.

$N u_{x} \quad$ : The local Nusselt number coefficient.

Pr : Prandtl number.

$p \quad$ : Fluid pressure.

$q_{w} \quad:$ Surface heat flux.

$T \quad$ : Temperature of the fluid.

$T_{w} \quad$ : Temperature at the surface.

$T_{\infty} \quad$ : Temperature of the ambient fluid.

$u$ : Velocity component in the $\mathrm{x}$ - direction.

$v \quad:$ Velocity component in the y-direction.

$V \quad:$ The transpiration velocity.
}

$x \quad$ : Measured from the leading edge.

$y \quad$ : Distance normal to the surface.

Greek symbols

$\alpha \quad:$ The thermal diffusivity.

$\beta \quad$ : Co-efficient of volume expansion

$\gamma \quad$ : The cone apex half-angle.

$\xi \quad:$ The dimensionless suction parameter.

$\eta \quad:$ The pseudo-similarity variable.

$v \quad:$ Kinematic viscosity

$\mu \quad$ : Viscosity of the fluid

$\theta \quad$ : Dimensionless temperature

$\rho \quad$ : Density of the fluid inside the boundary layer.

$\psi \quad$ : Stream function

$\in \quad:$ The pressure work parameter. 


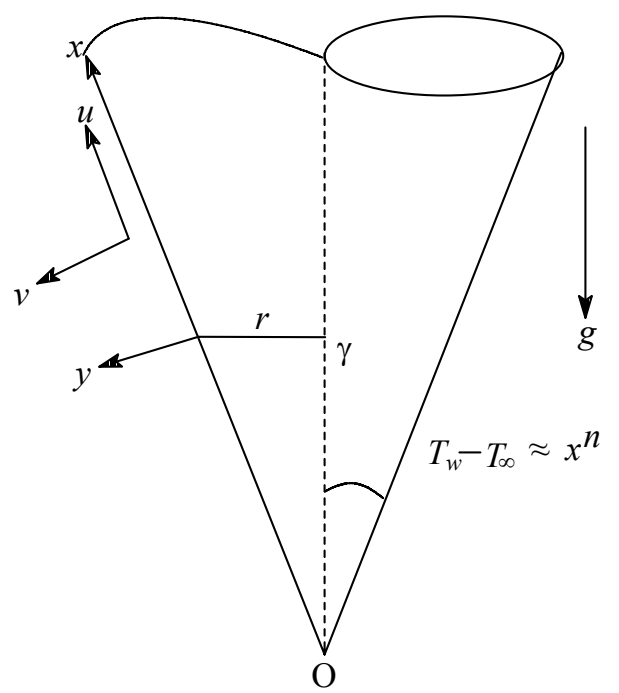

Fig. 1: Physical model and co-ordinates system

$\mathrm{Na}$ and $\mathrm{Chiou}^{6}$ studied the effect of slenderness on the natural convection flow over a slender frustum of a cone. The problem of natural convection flow over a frustum of a cone without transverse curvature effect (i.e., large cone angles when the boundary layer thickness is small compared with the local radius of the cone) has been treated in the literature, even though the problem for a full cone has been considered quite extensively by Sparrow and Guinle ${ }^{7}$, Lin $^{8}$, Kuiken $^{9}$ and Oosthuizen and Donaildson ${ }^{10}$. Later, $\mathrm{Na}$ and $\mathrm{Chiou}^{6}$ studied the laminar natural convection flow over a frustum of a cone. In the above investigations the wall temperature as well as the wall heat flux had been considered constant. On the other hand, Alamgir ${ }^{11}$ investigated the overall heat transfer in laminar natural convection flow from vertical cones by using the integral method. Gebhart ${ }^{12}$ dealt with the effects of viscous dissipation in natural convection flow. Hossain et.al. ${ }^{13}$ studied the effect of radiation on free convection from a porous vertical plate. Hassain et.al ${ }^{14,15}$ investigated the non-uniform surface temperature and heat flux over a free convection from a vertical permeable circular cone.

In the present study, we have investigated the laminar free convection flow from a vertical circular cone maintained at non-uniform surface temperature with suction and pressure work term that follows the power law variations with the distance measured from the apex of the cone. Under the usual Boussinesq approximation, the governing partial differential equations are reduced to locally non-similar partial differential equations. The transformed equations are solved numerically by using finite difference with Keller Box method. The solutions are obtained in terms of skin- friction and heat transfer for various values of Prandtl number $P r$, and temperature gradient parameter $n$, are displayed in tabular form as well as graphically. Also the effect of varying the Prandtl number $\operatorname{Pr}$, the surface temperature gradient $n$, the pressure work parameter $\in$ and the suction parameter $\xi$ are shown graphically in the velocity and temperature distributions.

\section{MATHEMATICAL FORMULATION}

A steady two-dimensional laminar free convection flow past a non-isothermal vertical porous cone with variable surface temperature is considered. The effect of viscous dissipation on thermal boundary layer is neglected. The physical coordinates $(x, y)$ are chosen such that $x$ is measured from the leading edge, $\mathrm{O}$, in the stream wise direction and $y$ is measured normal to the surface of the cone. The coordinate system and the flow configuration are shown in Figure 1.

The boundary layer equations for steady, axisymmetric, non-dissipative and constant property flow are given below.

$$
\begin{aligned}
& \frac{\partial(u r)}{\partial x}+\frac{\partial(v r)}{\partial y}=0 \\
& u \frac{\partial u}{\partial x}+v \frac{\partial v}{\partial y}=v \frac{\partial^{2} v}{\partial y^{2}}+g \beta \cos \gamma\left(T-T_{\infty}\right) \\
& u \frac{\partial T}{\partial x}+v \frac{\partial T}{\partial y}=\alpha \frac{\partial^{2} T}{\partial y^{2}}+\frac{T \beta u}{\rho C_{p}} \frac{\partial p}{\partial x}
\end{aligned}
$$

Where $u, v$ are the fluid velocity components in the $\mathrm{x}$ directions and y-directions respectively, $v$ is the kinematics coefficient of viscosity, $g$ is the acceleration due to gravity, $\beta$ is the coefficient of volume expansion, $\alpha=\kappa / \rho C_{p}$ is the thermal diffusivity, $\gamma$ is the cone apex half-angle and $T$ is the temperature of the fluid. The boundary conditions are as follows

$$
\begin{aligned}
& u=0, v=-V, T=T_{w}(x) \text { at } y=0 \\
& u=0, T=T_{\infty} \quad \text { as } y \rightarrow \infty
\end{aligned}
$$

Where $V$ represents the transpiration velocity of the fluid through the surface of the cone, $T_{\infty}$ is the ambient fluid temperature; $T_{w}$ is the surface temperature with $T_{w}>$ $T_{\infty}$. When $V$ is positive, it stands for suction or withdrawal and $V$ is negative for injection or blowing of fluid through the surface of the cone. In the present case, only suction is considered and therefore, $V$ is taken as positive throughout.

Since near the apex of the cone, the boundary layer is much similar that the free-convection boundary layer in the absence of suction, we can introduce the following transformations

$$
\begin{aligned}
& \psi=v r\left(G r_{x}\right)^{\frac{1}{4}}\left[f(\xi, \eta)+\frac{1}{2} \xi\right], T-T_{\infty}=\left(T_{w}-T_{\infty}\right) \theta(\xi, \eta) \\
& \eta=\frac{y}{x}\left(G r_{x}\right)^{\frac{1}{4}}, \xi=\frac{V x}{v}\left(G r_{x}\right)^{\frac{1}{4}}, r=x \sin \gamma \\
& G r_{x}=\frac{g \beta \cos \gamma\left(T-T_{\infty}\right) x^{3}}{v^{2}}, T_{w}-T_{\infty} \approx x^{n}
\end{aligned}
$$

Where $G r_{x}$ is the local Grashof number, $\xi$ is the dimensionless suction parameter, $\eta$ is the pseudo-similarity variable and $\psi$ is the stream function defined by

$u=\frac{1}{r} \frac{\partial \psi}{\partial y}$ and $v=-\frac{1}{r} \frac{\partial \psi}{\partial x}$

Finally, the functions $f(\xi, \eta)$ and $\theta(\xi, \eta)$ are, respectively, the dimensionless stream function and the temperature function of the fluid in the boundary layer region. Hence,

$$
u=\frac{v \sqrt{G r_{x}}}{x} \frac{\partial f}{\partial \eta}, \frac{\partial u}{\partial y}=\frac{v\left(G r_{x}\right)^{\frac{3}{4}}}{x^{2}} \frac{\partial^{2} f}{\partial \eta^{2}}, \frac{\partial^{2} u}{\partial y^{2}}=\frac{v G r_{x}}{x^{3}} \frac{\partial^{3} f}{\partial \eta^{3}}
$$


and

$$
\begin{aligned}
& v=\frac{v(n+7)}{4 x}\left(G r_{x}\right)^{\frac{1}{4}} f(\xi, \eta)-\frac{v \xi(n+7)}{4 x}\left(G r_{x}\right)^{\frac{1}{4}} \\
& -\frac{v \eta(n-1)}{4 x}\left(G r_{x}\right)^{\frac{1}{4}} \frac{\partial f}{\partial \eta}-\frac{v \xi(n+7)}{4 x}\left(G r_{x}\right)^{\frac{1}{4}} \frac{\partial f}{\partial \xi} \\
& \frac{\beta T}{\rho C_{p}} u \frac{\partial p}{\partial x}=-\frac{\rho g \beta T}{\rho C_{p}} u=-\frac{\in\left\{T_{\infty}-\left(T_{w}-T_{\infty}\right)\right\}_{0}}{x^{2}} \theta(\xi, \eta)\left(G r_{x}\right)^{1 / 2}\left(\frac{\partial f}{\partial \eta}\right)
\end{aligned}
$$

$g \beta x / C_{p}=\epsilon$, Which is pressure work parameter known as dissipation parameter used by Gebhart ${ }^{12}$.

Using the above transformations reduces to

$f^{\prime \prime \prime}+\frac{n+7}{4} f f^{\prime \prime}-\frac{(n+1)}{2} f^{\prime 2}+\theta=\frac{(n+7)}{4} \xi\left[f^{\prime} \frac{\partial f^{\prime}}{\partial \xi}-f^{\prime \prime} \frac{\partial f}{\partial \xi}-f^{\prime \prime}\right]$

Where $\left(T_{w}-T_{\infty}\right)=x^{n}$

Also the energy equation transforms to

$$
\frac{1}{P r} \theta^{\prime \prime}+\frac{n+7}{4} f \theta^{\prime}-[n+\in] \theta f^{\prime}=\frac{n+7}{4} \xi\left[f^{\prime} \frac{\partial \theta}{\partial \xi}-\theta^{\prime} \frac{\partial f}{\partial \xi}\right]
$$

The corresponding boundary conditions to be satisfied are: $f=f^{\prime}=0$ and $\theta=1$ at $\eta=0$

$f^{\prime}=0, \theta=0$ as $\eta \rightarrow \infty$

Where $\operatorname{Pr}=\nu / \alpha$ is Prandlt number and primes denoting differentiation with respect to $\eta$. For the flow from an impermeable surface (i.e., $\xi=0$ ), the equations (6) and (7) subjected to the boundary conditions (8) have been solved by Hering and Grosh [3] for non-isothermal surface. Solutions of the local non-similar partial differential equations (6) to (7) subjected to the boundary conditions (8) are obtained by using the implicit finite difference method, which has been used, by Hossain et al. ${ }^{13-15}$, Cebeci and Bradshaw ${ }^{17}$

Once we know the values of the functions $f$ and $\theta$ and also their derivatives, it becomes important to calculate the values of the local skin-friction co-efficient, $C_{f x}$ and the local Nusselt number $N u_{\mathrm{x}}$, from the following relations.

$C_{f x}=\frac{\tau_{w}}{\rho U^{2}}$ and $N u_{x}=-\frac{q_{w} x}{\kappa\left(T_{w}-T_{\infty}\right)}$

Where $\tau_{w}=\mu\left(\frac{\partial u}{\partial y}\right)_{y=0}$ and $q_{w}=-\kappa\left(\frac{\partial T}{\partial y}\right)_{y=0}$ are, respectively, the shear stress and rate of heat-flux at the surface and $U=v \sqrt{\left(G r_{x}\right)} / x$ is the reference velocity. Now

$$
\begin{gathered}
\tau_{w}=\mu\left(\frac{\partial u}{\partial y}\right)_{y=0}=\mu \nu \frac{\left(G r_{x}\right)^{\frac{3}{4}}}{x^{2}} \frac{\partial^{2} f(\xi, 0)}{\partial \eta^{2}} \\
q_{w}=-\kappa\left(\frac{\partial T}{\partial y}\right)_{y=0}=-\kappa \frac{x^{n}\left(G r_{x}\right)^{\frac{1}{4}}}{x} \frac{\partial \theta(\xi, 0)}{\partial \eta}
\end{gathered}
$$

Therefore, we have

$$
\begin{aligned}
C_{f x}=\frac{\tau_{w}}{\rho U^{2}} & =\mu \nu \frac{\left(G r_{x}\right)^{\frac{3}{4}}}{x^{2}} \frac{\partial^{2} f(\xi, 0)}{\partial \eta^{2}} / \frac{\rho v^{2} G r_{x}}{x^{2}} \\
& =\frac{\partial^{2} f(\xi, 0)}{\partial \eta^{2}} /\left(G r_{x}\right)^{\frac{1}{4}}
\end{aligned}
$$

Which implies that

$$
\begin{aligned}
& \left(G r_{x}\right)^{\frac{1}{4}} C_{f x}=\frac{\partial^{2} f(\xi, 0)}{\partial \eta^{2}} \\
& \text { Again } \\
& \begin{aligned}
N u_{x} & =\frac{q_{w} x}{\kappa\left(T_{w}-T_{\infty}\right)}=-\kappa \frac{x^{n}\left(G r_{x}\right)^{\frac{1}{4}}}{x} \frac{\partial \theta(\xi, 0)}{\partial \eta} / \kappa\left(T_{w}-T_{\infty}\right) \\
& =-\left(G r_{x}\right)^{\frac{1}{4}} \frac{\partial \theta(\xi, 0)}{\partial \eta}
\end{aligned}
\end{aligned}
$$

Therefore, $\left(G r_{x}\right)^{\frac{1}{4}} N u_{x}=-\frac{\partial \theta(\xi, 0)}{\partial \eta}$
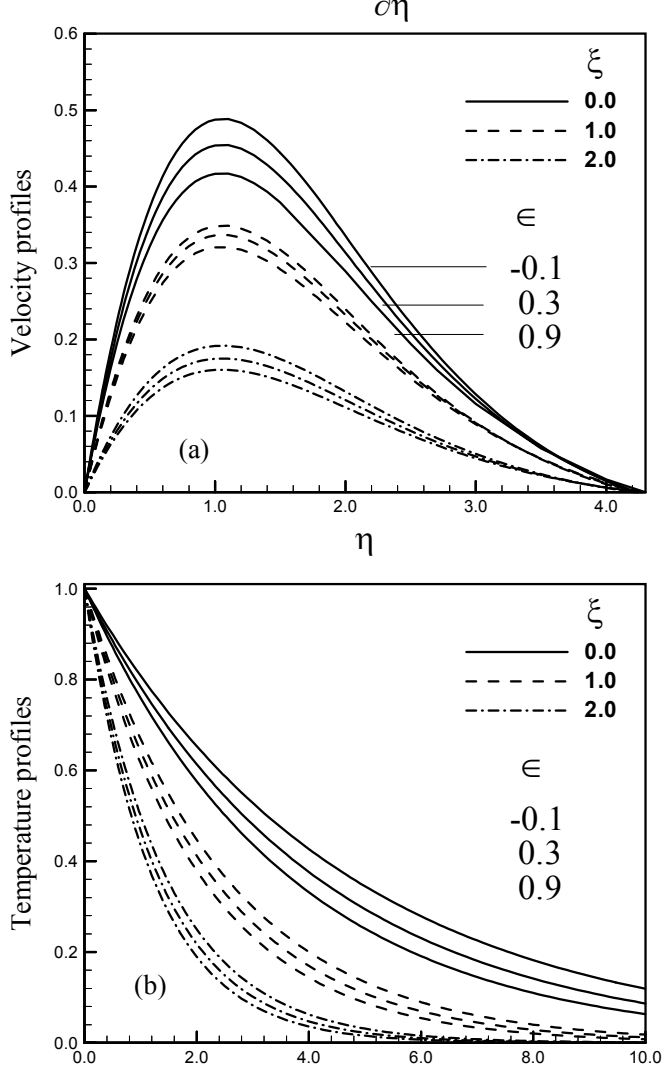

$\eta$

Fig. 2: (a) Velocity and (b) Temperature profiles against $\eta$ for different values of pressure work parameter $\in$ and suction parameter $\xi$ with $n=0.5, \operatorname{Pr}=0.72$

\section{RESULTS AND DISCUSSION}

In this paper we have investigated the effects of pressure work and suction on laminar natural convective flow and heat transfer from a vertical cone with nonuniform surface temperature. The solutions of the momentum and energy equations with the appropriate boundary condition are obtained by the finite difference method together with the Keller-Box scheme. Results are obtained in terms of local skin-friction, the rate of heat transfer, velocity and temperature profiles and presented graphically as well as in tabular form.

The effects of varying Prandtl number $\operatorname{Pr}(=0.72,1.0$, $3.0,5.0,7.0)$, pressure work parameter $\in(=-0.1,0.6,0.9)$ and temperature gradient parameter $n(=-0.45,-0.1,0.5$, $0.9,1.20)$ on the dimensionless velocity, $f^{\prime}(\xi, \eta)$ and the dimensionless temperature $\theta(\xi, \eta)$ against $\eta$, are shown in fig.2-4. 

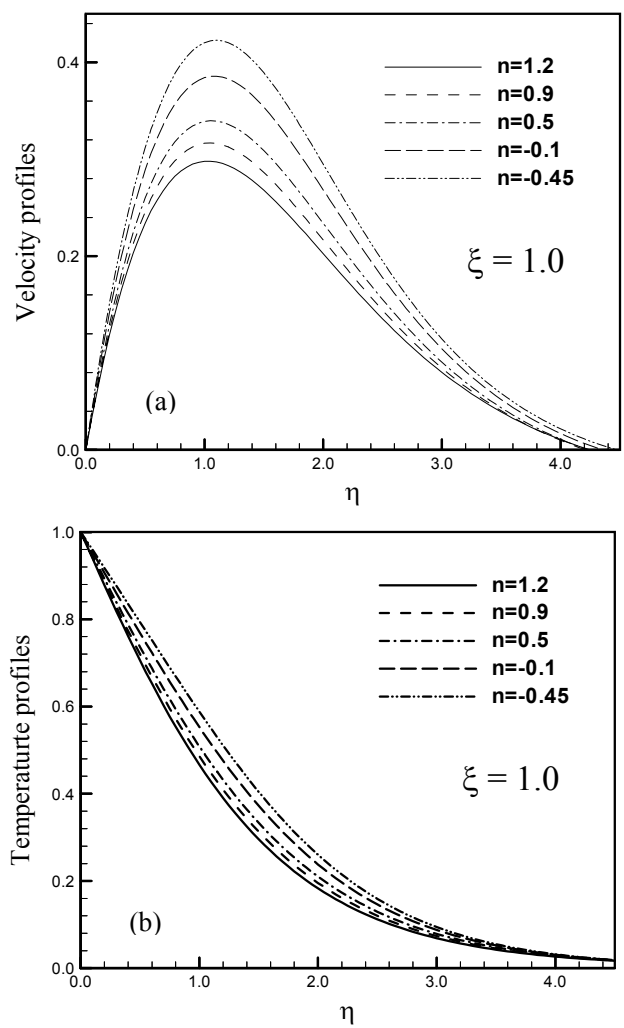

Fig. 3: (a) Velocity and (b) Temperature profiles against $\eta$ for different values of temperature gradient parameter $n$ with $\in=0.2, \operatorname{Pr}=0.72$
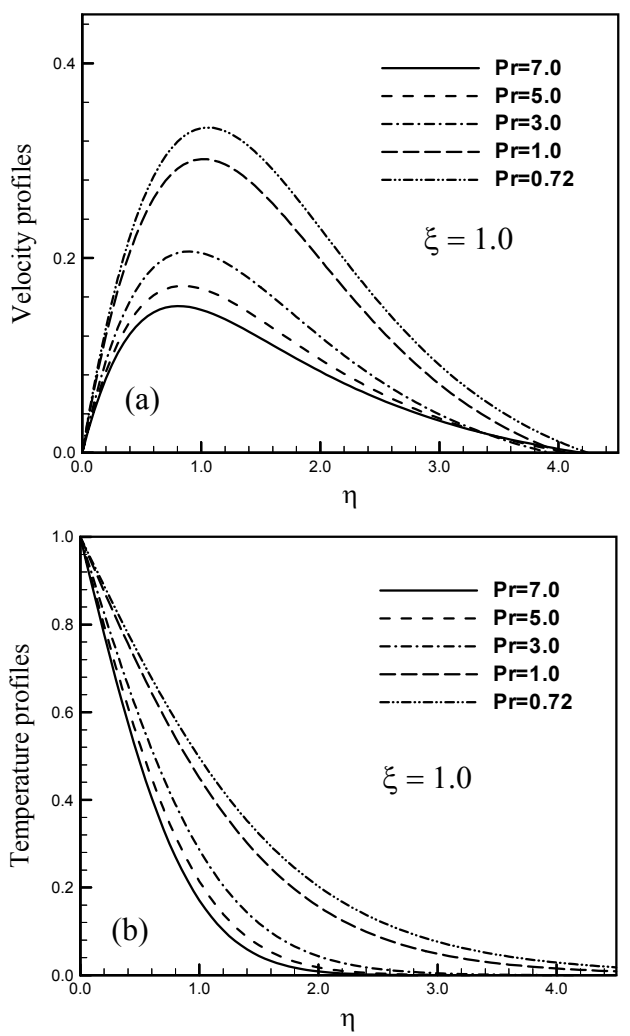

Fig. 4: (a) Velocity and (b) Temperature profiles against $\eta$ for different values of Prandtl number Pr with $\in=0.5$, temperature gradient parameter $n=0.4$
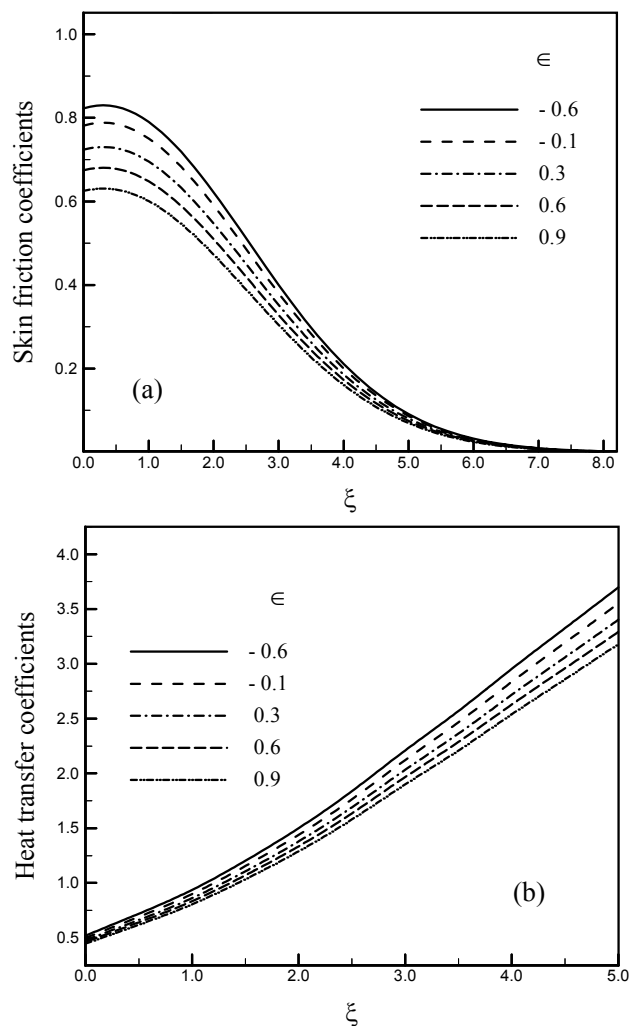

Fig. 5: (a) Skin friction and (b) Heat transfer coefficients against $\xi$ for different values of pressure work parameter $\epsilon$ with $\mathrm{n}=0.5, \operatorname{Pr}=0.72$
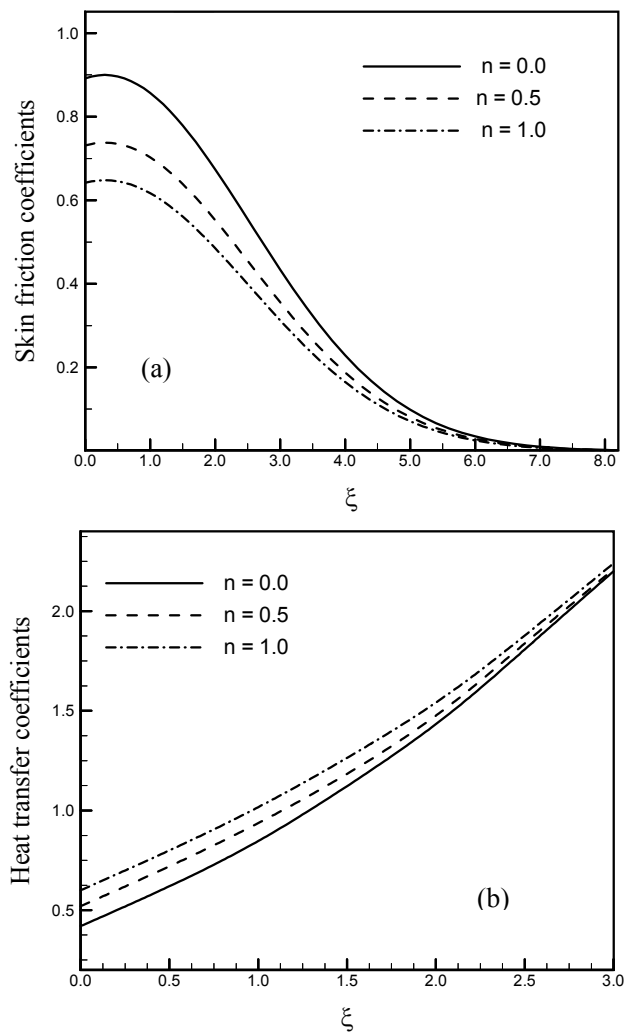

Fig. 6: (a) Skin friction and (b) heat transfer coefficients against $\xi$ for different values of temperature gradient parameter $n$ with $\in=0.2, \operatorname{Pr}=0.72$ 

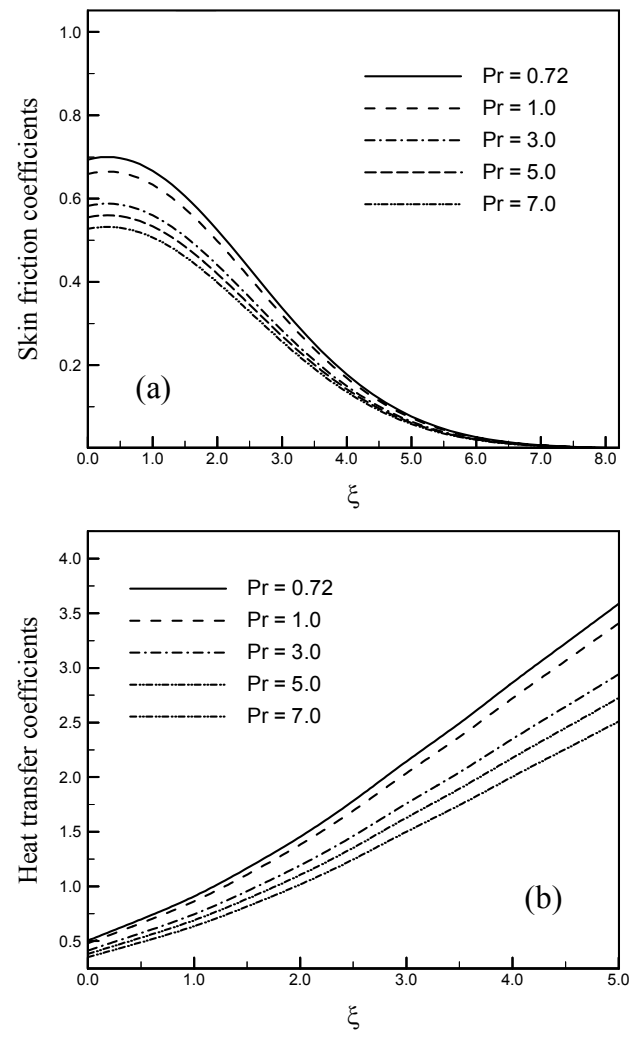

Fig. 7: (a) Skin friction and (b) heat transfer coefficients against $\xi$ for different values of Prandtl number Pr with $\epsilon$ $=0.3$, temperature gradient parameter $n=0.4$

The effects of varying Prandtl number $\operatorname{Pr}(=0.72,1.0$, $3.0,5.0,7.0)$, pressure work parameter $\in(=-0.1,0.6,0.9)$ and temperature gradient parameter $n(=-0.45,-0.1,0.5$, $0.9,1.20)$ on the dimensionless velocity, $f^{\prime}(\xi, \eta)$ and the dimensionless temperature $\theta(\xi, \eta)$ against $\eta$, are shown in fig.2-4. Also the skin friction and the rate of heat transfer against $\xi$ are shown in fig.5-7.

The numerical values of the dimensionless velocity and temperature profiles are shown graphically in figure 2(a) and 2(b), respectively for the different values of suction parameter $\xi=0.0,1.0,2.0$ and the pressure work parameter $\in=-0.1,0.3,0.9$ while $P r=0.72$ and temperature gradient $n=0.5$. In this figures the solid, dashed and dash dotted curves are used to represent for the various values of suction parameter $\xi(=0.0,1.0,2.0)$. From fig. 2(a), we observed that the velocity profiles decrease with the increase in the suction parameter $\xi$ and the pressure work parameter $\in$ respectively but the effects of suction on velocity and temperature profiles are higher than the effects of pressure work. Physically, the suction reduces the boundary layer thickness significantly and as a result velocity and temperature within the region. It can also observed that at each value of $\xi$ there exist local maxima in velocity profile within the boundary layer region. From figure 2(b) it can be seen that the temperature profile decreases owing to the increase in the suction parameter $\xi$ and the pressure work parameter $\in$. From fig.3, we observe that the velocity and temperature profiles decrease with the increasing values of temperature gradient parameter $n(=-0.45,-0.1,0.5,0.9,1.20)$ and with the fixed values of $\operatorname{Pr}=0.72, \epsilon=0.2$ and the suction parameter $\xi=$ 1.0. The effects of varying Prandtl number $\operatorname{Pr}(=0.72,1.0$, $3.0,5.0,7.0)$ on the dimensionless velocity, $f^{\prime}(\xi, \eta)$ and the temperature profiles, $\theta(\xi, \eta)$ against $\eta$ for the pressure work parameter $\in=0.5$, the temperature gradient parameter $n=0.4$ and the suction parameter $\xi=1.0$ are shown in fig.4. From these figures, it is seen that the velocity and temperature profiles decrease with the increasing values of $P r$. In case of water at $20^{\circ} \mathrm{C}(\mathrm{Pr}=$ 7.0), the free laminar boundary shows a sharp decrease compared to the effects in electrolyte solution such as salt water $(P r=1.0)$ and air $(P r=0.72)$ at $20^{\circ} C$ and $P r=3.0$, 5.0 have been used theoretically.

In Fig.5, the effects of the pressure work parameter $\epsilon$ on the local skin-friction coefficient and the local heat transfer coefficient are observed. From Fig.5 (a), it can be seen that an increase in the values of $\in(=-0.6,-0.1,0.3$, $0.6,0.9)$ leads to a decrease in the values of skin-friction coefficient for all $\xi$. From this figure we also observe that the skin friction decreases gradually after the position $\xi$ $=1.0$ to the point of separation located near $\xi=6.75$. Also in fig.5 (b), we see that the local heat transfer coefficient decrease with the increase of $\in(=-0.6,-0.1,0.3,0.6,0.9)$ for all $\xi$. The numerical values of local skin-friction coefficient, $C_{f x}\left(G r_{x}\right)^{1 / 4}$ smaller and local heat transfer coefficient, $\quad N u_{x} /\left(G r_{x}\right)^{1 / 4} \quad$ smaller, against suction parameter $\xi$ for different values of temperature gradient parameter $n(=0.0,0.5,1.0)$ with Prandtls number $P r=$ 0.72 and the pressure work parameter $\epsilon=0.2$ are displayed in Fig.6. From fig.6 (a) it can be seen that the skin friction coefficients decrease with the increase of temperature gradient parameter $n$. Also from Fig.6 (b), we observed that the heat transfer coefficients are increasing with the increase of temperature gradient $n$. This indicates that the heat transfer coefficients significantly depend on temperature gradient parameter $n$.

Table-1: Numerical values of skin-friction and heat transfer coefficient against $\xi$ for the different values of temperature gradient $n(=0.0,0.5,1.0)$ while $\operatorname{Pr}=0.72, \in=0.6$.

\begin{tabular}{|c|c|c|c|c|c|c|}
\hline$n$ & \multicolumn{2}{|c|}{0.0} & \multicolumn{2}{|c|}{0.5} & \multicolumn{2}{|c|}{1.0} \\
\hline$\xi$ & $f^{\prime \prime}(\xi, 0)$ & $-\theta^{\prime}(\xi, 0)$ & $f^{\prime \prime}(\xi, 0)$ & $-\theta^{\prime}(\xi, 0)$ & $f^{\prime \prime}(\xi, 0)$ & $-\theta^{\prime}(\xi, 0)$ \\
\hline 0.0 & 0.891936 & 0.420508 & 0.7313878 & 0.520629 & 0.642194 & 0.600726 \\
0.5 & 0.896407 & 0.620748 & 0.735054 & 0.720871 & 0.645413 & 0.800968 \\
1.0 & 0.856963 & 0.848025 & 0.702710 & 0.938134 & 0.617013 & 1.018231 \\
1.5 & 0.779210 & 1.129365 & 0.639025 & 1.196446 & 0.561095 & 1.276543 \\
2.0 & 0.674111 & 1.441742 & 0.552771 & 1.501815 & 0.485351 & 1.576906 \\
3.0 & 0.434152 & 2.202662 & 0.356004 & 2.212674 & 0.312589 & 2.242712 \\
\hline
\end{tabular}


In Fig.7, it is depicted that the local skin friction and local heat transfer coefficient are decreasing with the increasing of Prandtls number $\operatorname{Pr}(=0.72,1.0,3.0,5.0,7.0)$ for the fixed values of other controlling parameters $\in=0.3$ and $n=0.4$. As in the fig. 5 skin friction results in figures 6 and 7 also show gradual decrease after the position $\xi=1.0$ to the point of separation located near $\xi=6.75$, at which the flow separation occurs.

The skin friction and local heat transfer coefficients are tabulated in Table- 1 for various values of $n$. In Table-1, we see that the values of skin friction coefficient decrease with the increasing values of temperature gradient $n$ and the heat transfer coefficients increase with the increase of the temperature gradient parameter $n$.

\section{CONCLUSIONS}

The present paper deals with the effects of suction and pressure work on laminar free convection boundary layer flow from a vertical cone maintained at non-uniform surface temperature. Numerical solutions of the equations governing the flow in the entire $\xi$ (the scaled stream wise variable for the transpiration velocity) have been obtained by using the implicit finite difference method with KellerBox scheme. From the present investigations, we may conclude the following:

- The value of skin-friction coefficient increases with the increase in suction parameter, $\xi$, near the apex of the cone and its value decreases to the asymptotic value as $\xi$ increases and also the local rate of heat transfer coefficient increases due to the increasing values of $\xi$. Physically, increase of suction reduces the boundary layer thickness resulting the increase of skin-friction, which prevents the flow separation.

- For increasing values of temperature gradient $n$, the skin friction coefficient decreases but the value of the rate of heat transfer increases as the value of the temperature gradient increases.

- For increasing values of pressure work parameter $\epsilon$, the skin friction coefficient and the rate of heat transfer decrease.

- Due to the increase in temperature gradient, $n$, the velocity as well as the surface temperature decrease.

- The velocity and temperature distribution decreases with the increasing values of the pressure work parameter $\in$.

- The fluid velocity as well as the temperature profiles decreases owing to the increase in the values of Prandtl number, $P r$.

- Increase in the values of Prandtl number, $P r$, leads to decrease in the values of skin-friction coefficient and the local rate of heat transfer respectively.

\section{REFERENCES}

1. E. J. Merk, and J.A. Prinss, "Thermal convection in laminar boundary," Appl. Sci. Res., 4A, 11-24, pp.195-206, 1954.
2. W. H Braun, S. Ostrach and J. E. Heighway, "Free convection similarity flows about two-dimensional and axisymmetric with closed lower ends,' Int. J. Heat Mass Transfer, 2, pp. 121-135, 1961.

3. R.G. Hering, and R. J. Grosh, "Laminar free convection from a non-isothermal cone," Int. Heat Mass Transfer, 5, pp.1059-1068, 1962.

4. R.G. Hering, "Laminar free convection from a nonisothermal cone at low Prandtl numbers," Int. J. Heat Mass Transfer, 8, 1333-1337, 1965.

5. S. Roy, "Free convection over a slender vertical cone at high Prandtl numbers," ASME J. Heat Transfer, 101, pp. 174-176, 1974.

6. T. Y. Na and J. P. Chiou, "Laminar natural convection over a slender vertical frustum of a cone," Warme and Stoffubertragung, 12, pp. 83-87, 1979.

7. E.M. Sparrow and L. D. F. Guinle, "Laminar natural convection over a slender vertical frustum of a cone," Warme and Stoffubertragung, 12, pp. 83-87, 1968.

8. F. N. Lin, "Laminar free convection from a vertical cone with uniform surface heat flux," Letters in Heat and Mass Transfer, 3, pp. 45, 1976.

9. H. K. Kuiken, "Axisystemmetric free convection boundary layer flow past slender bodies," Int. J. Heat Mass Transfer, 11, pp. 1141, 1968.

10. P. H. Oosthuizen and E. Donaldson, "Free convection heat transfer from vertical cone," J. Heat Transfer, 94 C3, pp. 33, 1972.

11. M. Alamgir, "Over all heat transfer from vertical cones in laminar free Convection, an approximate method," ASME J. heat transfer, 101, pp. 174, 1989.

12. B. Gebhart, "Effects of viscous dissipation in natural convection," J. of Fluid Mech. 14, pp. 225, 1962.

13. M. A. Hossain, M. A. Alim and D. A. S. Rees, "The effect of radiation on free convection from a porous vertical plate," Appl. Mech. And Egg, 42, pp. 181, 1999.

14. M.A. Hossain and S.C. Paul, "Free convection from a vertical permeable circular cone with non-uniform surface temperature," Acta Mechanica, 151, pp. 103$114,2001$.

15. M.A. Hossain, and S.C. Paul, "Free convection from a vertical permeable circular cone with non-uniform surface heat flux," Heat and Mass Transfer, 37, pp. 167-173, 2001.

16. J. C.Butcher, "The Numerical Analysis of Ordinary Differential Equations Runge-Kutta and General Linear Methods," John Wiley \& Sons Ltd., New York, 1987.

17. Cebeci, T., \& Brashaw, P, "Physical and Computational Aspects of Convective Heat Transfer". Spring, New York, 1984. 